\title{
Aproximación a una teoría de los derechos humanos del consumidor en el mercado global y su tratamiento en el derecho constitucional peruano*
}

\author{
Julio Baltazar Durand Carrión ${ }^{a}$
}

\begin{abstract}
Resumen: Existe en la doctrina un debate con relación al carácter constitucional de los derechos del consumidor. Al respecto se han esgrimido una serie de argumentos que tratan de explicar su esencia, partiendo del derecho administrativo, del derecho civil, del derecho ordenador del mercado, de la teoría de los intereses difusos, entre otros. En este artículo se desplegará un desarrollo conceptual, sistémico y coherente con el fin de entender cuáles son los fundamentos iusfilosóficos que permitirían estudiar la naturaleza del derecho del consumidor, su esencia y el porqué de su tratamiento constitucional.
\end{abstract}

No se ha establecido, con la misma prolijidad con que se ha hecho para los derechos humanos de primera generación, un conjunto de garantías para los derechos sociales de manera suficiente, precisa y coherente, que les otorgue eficacia.

Palabras clave: derechos del consumidor; mercado; derechos humanos; perspectiva constitucional; relaciones de consumo; Defensoría del Pueblo.

Fecha de recepción: 20 de febrero de 2019 Fecha de evaluación: 4 de julio de 2019 Fecha de aprobación: 4 de julio de 2019

* El presente artículo es resultado de investigación del Centro de Estudios de Políticas de Protección al Consumidor de la Facultad de Derecho de la Universidad San Martín de Porres.

a Doctor en Derecho de la Pontificia Universidad Católica del Perú. Estudios de posgrado en Derecho de la Competencia (Escuela Iberoamericana de Defensa de la Competencia, en España); estudios de Propiedad Intelectual en la Universidad de Buenos Aires, Argentina; de Derecho Internacional (Comité Jurídico Interamericano de la Organización de Estados Americanos, en Brasil), y de Derecho de la Empresa y Arbitraje en el Washington College of Law American University (United States of America). Profesor de la Facultad de Derecho y de la Escuela de Posgrado de la Pontificia Universidad Católica del Perú, la Universidad San Martín de Porres, la Universidad de Lima y la Universidad ESAN-Escuela de Administración de Negocios. Premio Nacional a la investigación universitaria en posgrado, en el 2007, a nivel doctoral, del área Humanidades por la Asamblea Nacional de Rectores. Vicepresidente de la Sala de Defensa de la Competencia y Presidente de la Sala Especializada en Protección del Consumidor del Tribunal del Instituto Nacional de Defensa de la Competencia y Protección de la Propiedad Intelectual (2002-2006 y 2012-2017).

Correo electrónico: jdurandc@usmp.pe 
Cómo citar: Durand Carrión J. B. (2019). Aproximación a una teoría de los derechos humanos del consumidor en el mercado global y su tratamiento en el derecho constitucional peruano. Revista Prolegómenos, 22(44), pp. 117-142. DOI: https://doi.org/10.18359/prole.3960

\title{
Approaching a Theory of Consumer Human Rights in the Global Market and their Treatment by Peruvian Constitutional Law
}

\begin{abstract}
There is a debate in the doctrine regarding the constitutional nature of consumer rights. In this regard, a series of arguments have been used to explain their essence, based on administrative law, civil law, market law, diffuse interest theory, etc. This article provides a conceptual, systemic and coherent elaboration to understand the iusphilosophical foundations that would allow the study of the nature of consumer law, its essence, and the reason for its constitutional treatment.

A set of guarantees for social rights that are as meticulous as first-generation human rights has not been established in a sufficient, precise and coherent manner to make them effective.
\end{abstract}

Keywords: Consumer rights; market; human rights; constitutional perspective; consumer relations; Office of the Ombudsman

\section{Perspectivas da teoria dos direitos humanos do consumidor no mercado global e seu tratamento no direito constitucional peruano}

Resumo: Existe um debate na doutrina sobre a natureza constitucional dos direitos do consumidor. Nesse sentido, uma série de argumentos tem sido utilizada para explicar sua essência, com base no direito administrativo, direito civil, direito regulatório, teoria do interesse difuso, entre outros. Neste artigo, faremos um desenvolvimento conceitual, sistêmico e coerente, a fim de entender quais são os fundamentos jusfilosóficos que nos permitiriam estudar a natureza do direito do consumidor, sua essência e a razão de seu tratamento constitucional.

Não foi estabelecido, com a mesma prolixidade com que foi feito para os direitos humanos de primeira geração, um conjunto de garantias para os direitos sociais de maneira suficiente, precisa e coerente que os torne eficazes.

Palavras-chave: direitos do consumidor; mercado; direitos humanos; perspectiva constitucional; relações de consumo; Defensoria Pública 


\section{Naturaleza jurídica de los derechos del consumidor}

En efecto, el hombre, es decir, el ser humano, es sujeto de necesidades desde que nace e incluso desde antes de nacer, aunque en ese momento satisface sus necesidades a través de la madre. Por lo tanto, el hombre, en cuanto sujeto necesitado, acude al mercado para satisfacer sus requerimientos; una vez que se integra a este, establece relaciones con los agentes económicos para poder garantizar dicho fin. En ese tránsito del hombre hacia el mercado, el Estado ha establecido una serie de derechos y prerrogativas para el individuo, puesto que por mandato constitucional el fin supremo de la sociedad y del Estado es la persona humana. Aquellos derechos a los que específicamente nos referimos son los que hoy llamamos derechos del consumidor: el derecho a la información, a la idoneidad de productos y servicios, el derecho a la salud, la seguridad, el respeto a su intimidad y su dignidad, el derecho a la protección de sus intereses económicos, el derecho a la igualdad de trato en las transacciones comerciales - léase no discriminación-, el derecho a la reparación de los daños, el derecho a ser representado, entre otros.

Desde este punto de vista, el hombre como sujeto de necesidades se convierte en un protagonista del mercado, precisamente por su condición de consumidor. De ahí que tenga todo el derecho de exigir información adecuada, seguridad, trato justo, precios competitivos, calidad, garantía, etc., es decir, una serie de prerrogativas que no deben ser negadas ni discutidas por el sistema jurídico, para permitirle al individuo tomar una decisión de compra eficiente, libre de influencias negativas que limiten, restrinjan o mediaticen su accionar como agente dinámico del mercado.

En este contexto, el derecho del consumidor debe ser entendido, entonces, como un derecho subjetivo y personal; una vez transgredido, se debe proceder a su reparación, puesto que esa transgresión equivale a una violación de uno de los derechos de la persona y debe tener, jurídicamente, un tratamiento similar a cuando hay violación de la libertad, la intimidad o se vulnera cualquier otro atributo de la personalidad. Es decir, la violación del derecho del consumidor implica que el Estado ponga en juego todo su bosque normativo para proteger los intereses de aquel, sus derechos y sus prerrogativas, que el sistema jurídico ha creado para él, en cuanto persona humana consumidora.

La materialización de la protección a los consumidores es consecuencia del reconocimiento de la existencia de una gran mayoría de personas que, al realizar las operaciones normales de la vida diaria, no están en condiciones de conseguir por sí solas calidades y precios adecuados; estas personas se ven imposibilitadas para ejercer sus derechos por no contar con los recursos necesarios para enfrentarse a los productores y proveedores.

Lo expuesto implica, entonces, que no debemos limitar la protección de los consumidores a la etapa contractual de un acto de consumo, sino a los momentos anteriores también, puesto que, en otras palabras, se constata que los consumidores tienen muy pocas posibilidades de influir en el mercado, y que se ven sometidos a una extraordinaria presión por medio de la publicidad, que tiende a reducir su capacidad crítica. En este punto, el Estado interviene cada vez más con mayor amplitud, modificando, regulando normas jurídicas, en el campo de la publicidad, de la contratación, etc. Como el interés del consumidor ulteriormente protegido es un interés propio de la persona humana, proteger al consumidor significa en esencia proteger a la persona humana en cuanto es sujeto de necesidades y fin supremo de la sociedad y del Estado. Esta protección, a su vez, tiene un impacto positivo en las relaciones de consumo que se establecen diariamente, y ayuda a crear un mercado más grande y creciente, más transparente, más maduro y más competitivo, pues un adecuado sistema de protección del consumidor no se revela únicamente en la acción de sancionar, sino, sobre todo, en la prevención y en evitar conductas lesivas a los consumidores. Así, promueve una nueva cosmovisión del gobierno corporativo que respete las reglas del mercado y en especial los derechos de los consumidores, para ganar con ello una cultura de consumo responsable capaz de beneficiar a todos los actores vinculados en la protección del consumidor en general. 
Esta nueva concepción sobre el tema implica una nueva cosmovisión del sistema jurídico, en la que el eje sobre el cual giran las normas de protección al consumidor es la persona humana, que da significado existencial al mercado y, además, es el fin supremo de la sociedad y del Estado no solo por mandato constitucional, sino porque es el centro de referencia de todo sistema jurídico. Es, por ende, claro que la condición de consumidor es intrínseca a la condición misma de la persona humana en toda su esencia y sin condición alguna, porque el hombre, ontológicamente hablando, es sujeto de necesidades desde su nacimiento, e incluso desde antes, y por ello tiene el derecho de gozar de todas las prerrogativas y facultades que, en materia de consumo, el sistema jurídico ha creado para él. En efecto, todos los seres humanos somos consumidores y usuarios de bienes y servicios, y todas las actividades económicas que el hombre realiza, en una u otra medida, están destinadas a la satisfacción de necesidades; de ahí que el comercio esté destinado a satisfacer dichas necesidades, así como comodidades, gustos y hasta vanidades humanas.

No puede existir actividad comercial sin consumidores. Por esta razón, todos los empresarios, en calidad de proveedores, financiadores, programadores, etc., están identificados con la tarea de producir e intercambiar bienes y servicios con destino a la masa de aquellos, usuarios finales. El consumidor es quien da vida al mercado con sus innumerables actos de consumo, llevados a cabo diariamente en todos los mercados. Con justa razón, John Kennedy, el 15 de marzo de 1962, en su ya mítico discurso al Congreso norteamericano, expresó que los consumidores somos quienes damos vida al mercado. A pesar de esto, nuestras voces no son escuchadas.

El derecho del consumidor no es un estatuto, porque no existe una clase, o un gremio, o una profesión de consumidores; todos los seres humanos somos consumidores y coincidimos con el autor en señalar que hace unas décadas se había concebido al derecho comercial como derecho de la empresa, olvidando que la empresa existe, vive y actúa para llegar, de un modo u otro, hasta el consumidor y usuario final. (Farina, 1995). Por eso, algunos autores, guiados por una visión unilateral del derecho mercantil, olvidaron o consideraron extraños a él los derechos de quienes necesariamente dan razón de ser a esa actividad y, por lo tanto, al derecho comercial; no en vano últimamente se le conoce al consumidor como el protagonista del mercado.

Esta nueva concepción sobre el tema exige una nueva cosmovisión del sistema jurídico, que ponga a la persona humana como lo que es en realidad: el centro de referencia de todas las relaciones jurídicas que los sujetos de derecho establecen entre sí. En este nuevo sistema, es necesario que se revalúe el rol del consumidor como aquel que le da el impulso vital a la economía de mercado.

\section{Tratamiento constitucional de los derechos del consumidor}

En la Constitución Política del Perú, se señala en su artículo 65:

El Estado defiende el interés de los consumidores y usuarios. Para tal efecto garantiza el derecho a la información sobre los bienes y servicios que se encuentran a su disposición en el mercado. Asimismo, vela, en particular, por la salud y la seguridad de la población.

Este artículo denota contenido y propiedad en la determinación constitucional del Derecho del Consumidor, en cuanto es una disposición expresa de carácter constitucional, en la que se señala sin ambigüedad el alcance normativo de los derechos del consumidor, como un derecho merecedor de tutela jurídica, como un derecho inherente a la esencia misma de la persona humana, y que es a su vez una de las dimensiones quizá más importantes de la economía social de mercado establecida por nuestra constitución, en la medida en que el consumidor, dotado de naturaleza humana y sujeto de derechos, es el destinatario final de todas las transacciones del mercado.

Difícilmente habrá un mercado confiable y en expansión si el consumidor queda a merced del poder de quienes lo producen y distribuyen. Por ello, la Protección del Consumidor tiene importancia no solo por la justicia que busca para el individuo, sino también por la necesidad de fortalecer y hacer crecer el mercado. Justicia y conveniencia son dos 
aspectos que se entremezclan sustantivamente en este ámbito (Rubio, 1999).

No obstante, el artículo nos parece muy exiguo: creemos que la redacción pudo ser mejor, pues se menciona el interés del consumidor, mas no se trata el tema como un derecho de este, en cuanto persona humana y protagonista del mercado, así como tampoco se confirma la protección del Estado a él, como parte de su eje central de política en el mercado. En ese sentido, la redacción nos parece un tanto tímida o sugiere quizás que los legisladores pensaron que el tema era una obviedad y no aprovecharon el texto para hacer todo un desarrollo constitucional del tema con relación a la política de defensa del consumidor, que está relacionada con la dignidad de las personas, el fin supremo de la sociedad y del Estado.

Al sancionar la Constitución de 1993, se conoció que una de las intenciones de los constituyentes fue trasladar el eje de gravedad de la economía de empresa a la relación entre empresa y consumidor. Ello explica por qué la defensa del consumidor tiene una connotación importante en el esquema de economía imperante actualmente en el mercado (Torres y Torres Lara, 1994).

El derecho a la información de los consumidores respecto de los bienes y servicios que se ofertan en el mercado adquiere una connotación constitucional muy importante, que debe ser estudiada en función de otro derecho que también tiene raigambre constitucional: el derecho a la libre expresión. Esto, obviamente, exige una adecuada correlación para garantizar una información relevante y precisa, que permita un comportamiento eficiente por parte de los consumidores en el mercado.

Algunos tratadistas consideran que no es conveniente establecer una categoría constitucional para los derechos del consumidor, ya que podría convertirse en una simple norma programática. Sin embargo, lo más importante en esta materia es que el Estado promueva una legislación adecuada, así como los medios eficaces para que los consumidores y usuarios hagan valer sus derechos. Por lo tanto, no tiene ni puede hacer una referencia explícita sobre el alcance de la protección la declaración constitucional, puesto que la ley es la que debe definirla.
No obstante, la normatividad ha mostrado, en los últimos años, una particular sensibilidad creciente, con relación a la tutela jurídica del consumidor, en especial con aspectos relacionados con el derecho a la información, la seguridad de los productos y servicios ofrecidos en el mercado, las cláusulas abusivas en los contratos estandarizados y la responsabilidad de los productores por productos defectuosos. Se puede decir, entonces, que la legislación peruana es coherente con el movimiento universal contemporáneo de protección de los consumidores y su defensa organizada.

El Tribunal Constitucional ya ha efectuado una interpretación sobre el alcance normativo del artículo 65 de la Constitución y ha señalado con precisión:

La Constitución prescribe en su artículo 65 la defensa de los consumidores y usuarios, a través de un derrotero jurídico binario; vale decir, establece un principio rector para la actuación del Estado y simultáneamente, consagra un derecho subjetivo. En lo primero el artículo tiene la dimensión de una pauta básica o postulado destinado a orientar y fundamentar la actuación del Estado respecto a cualquier actividad económica. Así el juicio estimativo y el juicio lógico derivado de la conducta del Estado sobre la materia tiene como horizonte tuitivo la defensa de los intereses de los consumidores y los usuarios. En lo segundo, la Constitución reconoce la facultad de la acción defensiva de los consumidores y usuarios en los casos de trasgresión o desconocimiento de sus legítimos intereses; es decir apareja el atributo de exigir al Estado una actuación determinada cuando se produzca alguna forma de amenaza o de afectación efectiva de los derechos del consumidor o usuario, incluyendo la capacidad de acción contra el propio proveedor'.

En nuestro sistema, además del Indecopi, también existen organismos reguladores de los servicios públicos, que están legalmente facultados para regular la prestación de servicios de energía, telefonía, agua potable y alcantarillado y transportes. Por su naturaleza pueden establecer una serie

1 Sentencia del Tribunal Constitucional: sentencia 0008-2003-AI/TC. 
de disposiciones relativas a proteger al usuario e incluso, en sus procedimientos administrativos, incluyen la posibilidad de imponer sanciones pecuniarias para promover un mercado de servicios públicos transparente y sin perjuicios a los consumidores.

En el ámbito de la prestación de los servicios públicos de telefonía, energía, gas, agua e infraestructura de transporte de uso público, se han creado Osiptel, Osinergmin, Sunass y Ositran; todos tienen el genérico deber especial de protección de los derechos e intereses de los consumidores y usuarios, derivados de la prestación de los servicios públicos; la defensa de esto se encuentra en sus manos. De ahí que la ciudadanía pueda exigirles un rol activo y un papel garantista de los intereses y derechos de los consumidores frente a las amenazas o violaciones de los derechos fundamentales, que pudieran provenir de los agentes económicos que prestan dicho servicio público. De modo que dichos órganos reguladores tienen que adoptar todas las medidas necesarias, oportunas y eficaces para contrarrestar apropiadamente las lesiones o amenazas de violación de los derechos de los consumidores, las cuales generalmente se camuflan en cláusulas de adhesión, que no son adecuadamente informadas, y en las que eventualmente subyacen una serie de estipulaciones que no son negociadas y que conllevan situaciones de inequidad contractual generadoras de perjuicios a los usuarios, que no están en capacidad de discutir el contenido de los contratos de suministro de los servicios públicos.

La forma para que los organismos reguladores actúen eficazmente, con el fin de cumplir ese deber especial de protección ordenado por mandato constitucional, es impidiendo que los agentes económicos, dedicados a la prestación de los servicios públicos domiciliados y personales, vulneren los derechos que se puedan derivar de la suscripción de contratos de prestación de dichos servicios; además, impidiendo el abuso y, muy particularmente, el contenido desproporcionado de ciertas cláusulas de contratación que, en ese ámbito, se suelen insertar en tales contratos. En ese orden de ideas, los reguladores no solo están en la obligación de dictar todas las medidas reglamentarias adecuadas y necesarias de protección, sino, también, de realizar todas las acciones de control y supervisión sobre los entes prestadores de dichos servicios, con el fin de evitar que consumidores y usuarios puedan resultar lesionados en sus derechos e intereses legítimos.

Pero lo establecido en la Constitución no solo debe entenderse desde la perspectiva pública, es decir, considerar solo el derecho consagrado a los consumidores y el deber especial de protección que asumen las instituciones del Estado encargadas de vigilar el comportamiento de los agentes económicos en el mercado, sino que también debe entenderse como un mandato al sector privado, porque en el esquema de economía social de mercado, establecido en el artículo 58 del texto constitucional, las empresas privadas movilizan la economía; se reserva para el Estado, en este caso, un rol subsidiario, lo que significa que los agentes económicos tienen el deber de actuar dentro del marco de la legalidad e institucionalidad en el mercado y deben respetar los derechos de los consumidores, dejando de lado practicas poco éticas que ponen a los ciudadanos en situación de desventaja con cláusulas y con condiciones contractuales eventualmente abusivas, propias de un sistema contractual predeterminado y masivo, en el que la libertad de contratación, de negociación y reflexión esta mermada, desde diversas aristas y por una variedad de condiciones asimétricas.

Así, por ejemplo, el Tribunal Constitucional señala con precisión que, en el "principio de proscripción del abuso del derecho", "el Estado combate toda forma de actividad comercial derivada de prácticas y modalidades contractuales perversas que afectan el legítimo interés de los consumidores y usuarios" 2 . Como se puede apreciar lo que subyace en el fondo de este razonamiento constitucional es un llamado a los proveedores para que sean capaces de alinear sus conductas a un deber ser ético en los negocios.

2 Sentencia del Tribunal Constitucional EXP. N. 33152004-AA/TC 


\section{¿Derechos humanos en el mercado? Primeras aproximaciones hacia una nueva teoría de los derechos humanos del consumidor}

Tal como hemos expuesto en los párrafos anteriores, los derechos del consumidor tienen en esencia una raigambre constitucional, en la medida en que están referidos en el fondo a la persona humana, sobre todo, si el propio Tribunal Constitucional ha establecido previamente que se trata de un derecho con un derrotero jurídico binario, que establece, por un lado, un derecho al ciudadano y, por otro lado, impone un mandato de protección especial al Estado frente al ciudadano. Por lo tanto, creemos que es válido postular una aproximación teórica a los derechos humanos de los consumidores en el mercado, porque es evidente que en las prácticas de este se vulneran los derechos de aquellas, se trata de una realidad innegable. Se requiere, por ende, un enfoque sistémico y principista de derechos humanos para equilibrar las cosas y lograr el pleno ejercicio y respeto de los derechos fundamentales de las personas en el mercado.

Todos sabemos que los derechos humanos fueron, por siglos, defendidos del principal violador: el Estado, pues este, a través de sus agentes, llevaba a cabo una serie de actos de torturas, ejecuciones, encarcelamientos, persecuciones, entre otras violaciones a la dignidad humana. Una prueba de realidad es que, a nivel del sistema de derechos humanos, son los Estados los denunciados, porque se entiende que son los que violan los derechos humanos (acción) o los que no ha estructurado adecuadamente una norma o los procedimientos (omisión) para la defensa de los derechos, sean estos de primera, segunda o tercera generación, e incluso de la cuarta generación, de la que hoy se viene hablando en la nueva dogmática constitucional. En cualquier caso, el Estado no ha desarrollado los mecanismos más idóneos desde el punto de vista legal para proteger los derechos fundamentales de las personas y no ejerce sus prerrogativas para supervisar y vigilar las acciones de los estamentos estatales y de gobierno que, en su acción, suelen violentar los derechos de los ciudadanos, so pretexto del orden, la seguridad interna, la defensa nacional, la gestión pública eficiente y el desarrollo nacional, entre otras justificaciones.

Este discurso ya se ha asumido jurídicamente por muchos Estados y se ha convertido en paradigma de las teorías jurídicas y normativas sobre los derechos humanos. De ahí que, en todo lo que es garantismo de los derechos humanos de primera generación, ya existan las normas, las leyes, los tratados, la judicatura y la jurisprudencia, para garantizar adecuadamente dichos derechos; eventualmente se denuncian y sancionan los Estados ante cualquier violación de aquellos. Por esta razón, argumentamos que todo este sistema ya está jurídicamente estructurado y se desenvuelve y desarrolla de manera general, con eficiencia y solvencia académica y legal, continua y sostenible; sin embargo, en relación con los derechos y prerrogativas de las personas en el mercado, no podemos decir lo mismo, pues existe un vacío que la dogmática constitucional no ha llenado, quizá porque en este caso los actores principales, que eventualmente violentan a los consumidores en el mercado, son los operadores de mercado, que no pertenecen propiamente al Estado, pero sí, mediante sus dinámicas mercantiles, muchas veces suelen transgredir de manera sostenida los derechos de las personas, creando inequidades que no podemos negar ni discutir, y que necesitan ser sancionadas por el ius imperium del Estado.

Aunque parezca muy osado el planteamiento, consideramos que hay una buena base doctrinaria que sustenta nuestra propuesta. En ese sentido, es obvio que se necesita establecer con precisión un enfoque garantista de los derechos del consumidor $y$, por ende, proponemos una teoría de garantismo en los derechos del mercado, en función del eje principal de este: el consumidor, la persona humana, que, según el artículo 1 de la Constitución, es el fin supremo de la sociedad y el Estado.

Actualmente, la propuesta del modelo garantista de Luigi Ferrajoli es sin duda una de las más innovadoras líneas de pensamiento jurídico de la cultura jurídica en el campo de los derechos fundamentales; giran en torno a su teoría una serie de debates desde distintas perspectivas, en torno 
a la progresiva evolución de las generaciones de derechos humanos. En efecto, como es sabido, en primer lugar, surgieron los derechos civiles y políticos, reconocidos en las revoluciones liberales; en segundo lugar, nacen los derechos de segunda generación, como los derechos económicos, sociales y culturales, acaecidos partir de la Revolución Industrial del siglo XIX, y en tercer lugar, surgen los derechos de tercera generación, que constituyen fundamentalmente derechos de conquista, de carácter plural y de carácter social amplio y propios de nuestra sociedad actual, tales como el derecho a un medio ambiente saludable, la libertad cultural y los derechos colectivos, entre otros.

Es en este contexto histórico en el que encontramos el origen de la teoría garantista ferrajoliana, que postula la función del derecho como un sistema de garantías, constitucionalmente estructurado en función de la tutela de los derechos fundamentales. En este sentido, mediante el modelo garantista de derechos se propone un cambio estructural en la aplicación del derecho y la concepción de la democracia, que se traduce en el imperativo jurídico de la sujeción de toda forma de poder al derecho, tanto en el plano de procedimiento como en el contenido de sus decisiones. Luigi Ferrajoli comienza su argumentación con el reconocimiento de una fuerte crisis, que se ve reflejada en una crisis de legalidad, una crisis del Estado social y una crisis del Estado-nación. Este complejo fenómeno ha terminado en una grave desestabilización de la democracia. Ante esta situación se postula el sistema garantista, que surge para remediar el caos normativo, la proliferación de fuentes, la violación sistemática de las reglas por parte de los titulares del poder público, la ineficacia de los derechos y la incertidumbre e incoherencia del ordenamiento jurídico actual (Ferrajoli, 1998, pág. 868-880). De esta forma, el garantismo se presenta en tres planos:

1. Nuevo modelo normativo del derecho. Se caracteriza como un sistema de poder mínimo que concibe los derechos fundamentales como límites, a través de los cuales se maximiza la libertad y se minimiza la arbitrariedad e impunidad por parte de los gobernantes. Con ello propone una reestructuración de la democracia, desglosada en dos dimensiones claras y distintas: democracia formal (relacionada con el procedimiento de toma de decisiones) y democracia sustancial (relativa a los derechos fundamentales).

2. Teoría del derecho y crítica del derecho. El proceso histórico de positivización de los derechos responde al paradigma o modelo tradicional de positivismo jurídico. Sin duda alguna, éste ha sido un referente claro de influencia y continuidad en su visión del garantismo jurídico. La positivación de los derechos fundamentales ha vivido sucesivas etapas históricas, una de ellas ha sido la creación del Estado liberal de derecho que brindó en su momento seguridad jurídica a los ciudadanos.

3. Filosofía político-jurídica. El garantismo como doctrina filosófico-política permite la crítica de las instituciones jurídicopositivas, siguiendo el criterio de la clásica y rígida separación (propia del positivismo) entre derecho y moral o entre validez y justicia. (Aguilera y López, 2011, pp.52-53).

Si revisamos la teoría sobre derecho el consumidor, podemos darnos cuenta de que el desarrollo de esta disciplina, que es joven en su sistematización y construcción categorial, tiene un fundamento iusfilosófico rico en contenido y en esencia, que le permite nutrirse con suficiencia conceptual para hablar de un razonamiento teórico de derechos humanos en el mercado. En efecto, el proceso histórico de positivización del derecho del consumidor lo ubicamos primero en el derecho mercantil, en el que se concebían las normas del consumidor no pensando en la persona humana como sujeto de necesidades, sino fundamentalmente en las normas de protección de los gremios comerciales, cuyas reglas promovían el comportamiento de los agentes para preservar ciertas condiciones de mercado. Luego con el surgimiento del derecho civil y las normas contractuales se establecieron también ciertas reglas pensando, a su vez, en la fluidez del mercado y la facilitación de las transacciones comerciales (cláusulas generales de contratación y contratos por adhesión), hasta que van apareciendo las notas distintivas de la disciplina del derecho del consumidor, que concibe las reglas como una necesidad de respetar la esencia de las personas como sujetos de derechos y cuyas prerrogativas, 
que el sistema jurídico ha creado para ellas, deben ser respetadas también en el entorno de la dinámica comercial de los mercados. Así, es válida una crítica al iuspositivismo inicial del derecho del consumidor, aunque hoy se ha variado la cosmovisión del sistema jurídico de protección del consumidor, a través de una mirada más enfocada en la persona: la razón iusfilosófica de toda la ciencia del derecho.

El derecho del consumidor es, en esencia, un sistema legal de normas, principios e instituciones con una concepción principista y valorativa, que no implica la consideración de si la ley es buena o mala, sino que denota un acercamiento sistémico a la realidad del mercado, que busca en el fondo la justicia, la equidad, la validez y la eficacia de las normas. En ese sentido, está de acuerdo con el razonamiento garantista, el discurso dogmático y la teoría del derecho de la disciplina del derecho del consumidor como un derecho Social.

Por otra parte, el Estado, telón de fondo del sistema jurídico, es un fin y encarna en su esencia principios y valores sociales, éticos, políticos, filosóficos y constitucionales, que van más allá de la persona humana como sujeto de derecho y son de carácter social amplio y, por lo tanto, supraindividuales. En función de aquellos debe crearse un sistema jurídico adecuado y coherente que permita instrumentalizar y materializar los derechos. Es el Estado, entonces, el que está social y políticamente autorizado o, mejor dicho, legitimado para garantizar el pleno ejercicio de los derechos fundamentales de los ciudadanos; jurídicamente, además, es un actor importante en la escena del mercado y en la construcción de un sistema garantista de los derechos humanos de los ciudadanos consumidores. En este artículo, proponemos la urgente construcción de un sistema de protección de los derechos humanos para los consumidores en el mercado, sobre todo, en las actuales circunstancias de economía de mercado y de tendencias liberales cada vez más totalizadoras, crecientes y extendidas, que reducen la tutela garantista del Estado solo a favor de intereses económicos.

En este punto, debemos entender la concepción de las normas jurídicas no como objeto preexistente, sino como el producto (opinable y mutable) de la interpretación y las manipulaciones de los juristas (Guastini, 1999, pp. 29-45).

Ferrajoli entiende el universo del discurso como "el conjunto de cosas y/o experiencias de las cuales la teoría del derecho habla", y por dogmática jurídica: "el conjunto de los conceptos y de los enunciados dedicados a la clarificación del sentido de las normas, elaborados y a la vez verificables o refutables mediante el análisis del lenguaje legal, formulado en un lenguaje metalingüístico respecto de éste y que de él extrae dogmáticamente sus propias reglas de uso" (Ferrajoli, 2004, p.880).

El garantismo, entonces, desde un plano filosófico-político, consiste en la fundamentación heteropoyética del derecho, separado de la moral en los diversos significados. De esta manera, la deslegitimación externa de las instituciones jurídicas positivas dependerá directamente de la eficacia con la que esos derechos sean cumplidos (Aguilera y López, 2011, p. 55).

Los derechos sociales pueden considerarse como derechos a prestaciones en sentido estricto, que consisten en "derechos del individuo frente al Estado a algo que - si el individuo poseyera medios financieros suficientes y si encontrase en el mercado una oferta suficiente - podría obtenerlo también de particulares"; en consecuencia, su reivindicación interesa a todas las personas, pero fundamentalmente a los miembros más vulnerables de la sociedad, cuyo acceso a dichos recursos suele ser escaso y a veces nulo o inexistente. (Alexy, 2002, p. 482). En efecto, tal como señala el autor, consideramos que, si se revisa el derecho del consumidor, podemos verificar su carácter social amplio, que subyace de su naturaleza jurídica de disciplina de protección de intereses difusos; además, en su estructura normativa existen una serie de derechos y prerrogativas ciudadanas que tienen una serie de lagunas, imperfecciones y conculcaciones sin formas de garantías. Esto lo diferencia de otros derechos fundamentales como la vida, la libertad, entre otros, que sí tienen instituciones estructuradas jurídicamente para su defensa constitucional.

Luigi Ferrajoli observa cómo estos derechos sociales sufren una laguna de garantías, imperfecciones e incluso de conculcación. La ciencia 
jurídica no ha elaborado aún formas de garantías para los derechos sociales, con eficacia y sencillez, a diferencia de las previstas para los demás derechos fundamentales como los de libertad y autonomía. Los derechos sociales imponen deberes de hacer, por lo que su violación no se manifiesta, por lo tanto, como en el caso de la libertad, en la falta de validez de actos que pueden ser anulados por vía jurisdiccional, sino en lagunas de disposiciones o en carencias de prestaciones que reclamarían medidas coercitivas no siempre accionables. Esto se debe a que los problemas suscitados por los derechos sociales son, sobre todo, de carácter económico y político, tanto porque estos derechos tienen unos costos elevados como por todo el complejo y aparatoso sistema de mediación burocrática del Estado de bienestar (Aguilera y López, 2011, p. 66).

Las garantías primarias y secundarias tienen estrecha vinculación con la actividad denominada iuspositivismo crítico, propuesta por Ferrajoli. Esta práctica consiste en "la tarea científica del jurista de valorar la validez o invalidez de las normas conforme a parámetros tanto formales como sustanciales establecidas por normas de rango superior". Mientras que las lagunas deónticas son "generadas por la carencia de garantías", las lagunas jurídicas se deben a "la carencia de los presupuestos normativos u organizativos" para hacer efectivos los derechos. (Ferrajoli, 1998, p. 874).

Por otro lado, contemporáneamente, los valores jurídicos universales que han fundamentado los derechos humanos han sido la vida, la dignidad humana, la igualdad, la libertad y la fraternidad. Estos valores pueden ser vistos desde distintos enfoques, debido a su enorme riqueza conceptual. En lo que respecta a su tratamiento técnico-jurídico, aquellos conceptos aportan un alto grado de confusión como principios fundacionales de los derechos humanos. En este tenor, podemos hablar de libertad social, política, jurídica, psicológica, metafísica, moral, libertad-autonomía (Kant), libertad-participación (Hegel), libertad-prestación (Marshall), libertad positiva o negativa (I. Berlin). De esta manera, Ferrajoli propone una redimensión de los criterios axiológicos que fundamentan los derechos fundamentales. Entre estos valores se encuentran la igualdad, la democracia, la paz y la tutela del más débil. (Aguilera y López, 2011, p. 67).

Lo señalado con anterioridad, en nuestro concepto, es sin duda muy cierto y se debería atender para los derechos del consumidor, porque la dogmática de los derechos humanos no ha elaborado, con la misma prolijidad que lo ha hecho para los derechos humanos de primera generación, un conjunto de garantías para los derechos sociales con suficiencia teórica conceptual, precisión normativa y coherencia sistémica que les otorguen eficacia y eficiencia en su tratamiento jurídico. Por ello, estamos de acuerdo con que los derechos del consumidor, en cuanto derechos sociales a decir de Ferrajoli, imponen deberes de hacer, de actuar y de presionar socialmente al Estado. Hay que tener en cuenta que su violación no se manifiesta, como en el caso de la libertad, en la falta de validez de actos que pueden ser anulados por vía jurisdiccional, sino en lagunas de disposiciones o en regulaciones administrativas ineficientes e inocuas, descontextualizadas de la realidad, o en carencias de prestaciones que reclamarían medidas coercitivas no siempre eficientes, porque son generalmente determinadas por autoridades administrativas limitadas en sus funciones y que, en sus razonamientos jurídicos, no se atreven a superar el statu quo de un derecho anquilosado y de bases romanistas, inadecuadas con la realidad y la dinámica del mercado actual cada vez más creciente y extendido.

Esto lo suscribimos, porque en nuestra experiencia en el Tribunal del Instituto Nacional de Defensa de la Competencia y Protección de la Propiedad Intelectual (Indecopi), ejerciendo como Vicepresidente de la Sala de Defensa de la Competencia (2002-2006) y Presidente de la Sala Especializada en Protección al Consumidor (2012-2017), hemos defendido fehacientemente postulados que coinciden con lo expresado anteriormente en este artículo. Hemos propuesto nuevas líneas de pensamiento jurídico que muchas veces no podían establecerse con facilidad en las resoluciones, puesto que teníamos que enfrentarnos a interpretaciones clásicas y eventualmente descontextualizadas de la realidad, en la medida en que estaban basadas en instituciones jurídicas que el día de hoy han sido reformuladas o superadas, y que nosotros 
nos encargamos de revisar y sistematizar, pero con fundamentos iusfilosóficos, jurídicos y económicos. La finalidad de todo esto era proponer a nuestros colegas una forma de entender, razonar y resolver los conflictos de consumo, más allá de las figuras clásicas del derecho civil de base romanista, pensadas para un mundo jurídico que no corresponde con el actual.

Puedo señalar, incluso, que muchas de nuestras líneas de pensamiento de avanzada en materia de protección del consumidor, cuando no eran acogidas por nuestros pares, dieron lugar a sendos votos singulares, muchos de los cuales han sido ratificados en sede judicial cuando se han planteado acciones contencioso-administrativas.

Toda esta labor jurisprudencial se ha plasmado en resoluciones del Tribunal y votos singulares que, por lo demás, se pueden visualizar en nuestra palestra académica y virtual, con la cual seguimos debatiendo y proponiendo temas para la construcción de nuevos enfoques jurídicos en la defensa de los derechos del consumidor en el Perú ${ }^{3}$.

Asimismo, suscribimos lo señalado por el maestro Ferrajoli cuando expresa que los problemas suscitados por los derechos sociales son, sobre todo, de carácter económico y político, tanto porque estos derechos tienen unos costos elevados como por todo el complejo y aparatoso sistema de

3 El blog La Cátedra del Consumidor es un espacio virtual visitado por más de doscientos sesenta mil lectores hasta diciembre de 2018. Fue creado para compartir con la comunidad ideas y líneas de pensamiento jurídico innovadoras en materia de protección al consumidor, publicidad comercial, competencia desleal, libre competencia y barreras de acceso al mercado, entre otras; hemos mantenido como eje central la figura del consumidor, el protagonista del mercado. El objetivo es contribuir al debate académico y social sobre los temas de mercado, consumo, políticas públicas y el rol de las instituciones vinculadas a la supervisión del mercado, para promover una cultura de consumo responsable, buenas prácticas de gobierno corporativo y responsabilidad social empresarial, con una mirada sistémica enfocada en el derecho del consumidor como persona humana. El blog se puede visitar en el siguiente enlace: http://blog. pucp.edu.pe/blog/competenciayconsumidor/ mediación burocrática del Estado de bienestar. (Aguilera y López, 2011, p.66). Esta es una razón más para plantear un garantismo real y efectivo destinado a los derechos del consumidor en el mercado y para, igualmente, promover en las instituciones vinculadas al mercado una mirada y un enfoque más tuitivo, principista y humano en su actuación y en sus razonamientos. El establecimiento de garantías está relacionado con el iuspositivismo crítico, que impone a los actores y juristas la tarea de valorar la validez o invalidez de las normas, en este caso del derecho del consumidor, conforme a parámetros y estándares formales y sustanciales de rango superior, es decir, inspirados en los valores éticos y filosóficos que el derecho, ciencia social, nunca debe perder de vista, porque tal como establece Ferrajoli ( 2004, pp.161-165) mientras que las lagunas deónticas son "generadas por la carencia de garantías", las lagunas jurídicas consisten en "la carencia de los presupuestos normativos u organizativos" para hacer efectivos los derechos.

Los valores jurídicos universales que han fundamentado los derechos humanos - la vida, la dignidad humana, la igualdad, la libertad y la fraternidad - no se pierden en la estructura de los derechos del consumidor, porque están inmersos en ellos, hasta tal punto que en cada norma que establece un derecho del consumidor subyacen sin duda prerrogativas de derechos fundamentales y constitucionales. Veremos, por ejemplo, que detrás de cada reclamo hay un drama social y humano que no se puede desconocer. De ahí que se deba reclamar un razonamiento de derechos humanos en el tratamiento jurídico estos derechos. En efecto, cada vez que hay una reclamación de derecho del consumidor - por discriminación en el acceso a consumo, cobro de intereses no pactados, métodos de cobranza abusivos, bullying en los colegios, falta de idoneidad en la atención médica, cláusulas abusivas en los contratos de seguros, malas prácticas de atención a los clientes en los servicios públicos de transporte en general, faltas que violan las normas de etiquetado en los productos, falta de idoneidad en alimentos poco saludables, entre otros-, estamos sin lugar a dudas frente a una denuncia cuyo ropaje jurídico guarda también una prerrogativa de derechos fundamentales como la 
igualdad, la dignidad, el trato justo, el derecho a la salud, el derecho a la educación, el deber de información, la libertad, la intimidad, etc.

Así, Ferrajoli propone una redimensión de los criterios axiológicos que fundamentan los derechos fundamentales. Entre estos valores se encuentran la igualdad, la democracia, la paz y la tutela del más débil. Este postula, además, cuatro dimensiones de la cuestión planteada: razón o fundamento teórico; la fuente o el fundamento jurídico; la justificación o el fundamento axiológico, y el origen o fundamento histórico y sociológico. La justificación o fundamento axiológico de los derechos fundamentales se ubica en el contexto de la filosofía política o de la justicia. Para este propósito, Ferrajoli formuló a su vez criterios que permiten reconfigurar el fundamento axiológico de los derechos humanos: la conexión entre derechos fundamentales e igualdad; la conexión entre derechos fundamentales y democracia, y la conexión entre derechos fundamentales y paz. La teoría del maestro italiano concibe a la democracia constitucional bajo dos ópticas: una procedimental y otra sustancial (Ferrajoli, 1999, p. 314).

Para Ferrajoli, la sociedad actual se encuentra en un estado salvaje de naturaleza, ya que la ley del más fuerte en materia económica, política o social impera sobre la legalidad y el Estado de derecho (Ferrajoli, 1999, p. 316); esto afecta, sin lugar a duda, los derechos de los consumidores que son débiles frente al poder económico, aquellos que están inmersos en una dinámica de mercado creciente que propone anular toda regulación estatal so pretexto del modelo económico. De ahí que sea importante plantear una postura reivindicadora que ponga a la persona humana como centro de referencia del sistema jurídico en materia de mercado y, a su vez, establecer un sistema garantista de los derechos de aquella.

Por ello, concordamos con Aguilera y López al señalar:

Constitución no es sólo norma, sino cultura e integración social y ciudadana, por lo cual debemos acudir a un amplio proceso constituyente que propicie y busque el máximo consenso posible entre todos los interlocutores y afectados. Esto significa un pacto constitucional ampliamente legitimado por la sociedad civil a través del cual los ciudadanos se sientan partícipes y sujetos activos del proceso de construcción nacional. [...]

El Estado, por tanto, está compuesto por ciudadanos, y la norma constitucional posibilita la integración efectiva y aglutinación de una comunidad de ciudadanos a nivel interno. El problema, desde nuestro punto de vista, es encontrar la forma de alcanzar un constitucionalismo integrador no estratégico o instrumental que al final no concluya en mero nominalismo y normativismo vacío con la consiguiente separación drástica entre Constitución formal y Constitución materia. (2011, p. 70)

En este contexto, los peruanos debemos asumir un pacto social renovador capaz de conducirnos a una forma de convivencia que nos permita a todos como ciudadanos cumplir nuestro rol y nuestro proyecto vital. Para cumplir con este propósito, el respeto a las reglas del mercado y el respeto a los derechos del consumidor, impulsado gracias a una perspectiva humanista, es fundamental para convivir en paz y sobre todo para convivir con valores, con altura y con principios éticos, fieles a nuestra condición humana.

Por otra parte, también es importante no perder de vista en esta propuesta de garantismo constitucional, en materia de consumidor, la línea de pensamiento filosófico de la escuela del derecho natural. En efecto, después de haber hecho un estudio y un análisis de las aristas constitucionales del derecho del consumidor, consideramos que es preciso entender que este, tal como lo entendemos dentro de los postulados del iusnaturalismo, constituye un instrumento de superación de la desigualdad existente entre los proveedores y los consumidores y, en ese sentido, es lógico que el Código de Protección y Defensa del Consumidor se encuentre dirigido a proteger a aquellos individuos afectados por la desigualdad en la relación de consumo, es decir, a los consumidores: destinatarios finales de los bienes y servicios en el mercado.

La materialización de las regulaciones sobre la problemática del consumidor estará siempre orientada a buscar el bienestar social y económico del hombre como protagonista del mercado y como centro de referencia de todas las disposiciones del 
sistema jurídico. El derecho también busca la paz y el orden que deben ser garantizados por las disposiciones sobre protección del consumidor, desde una perspectiva del derecho Natural y, en este sentido, estas deben vincularse con la producción y comercialización de bienes y servicios para no quedar expuestas a la arbitrariedad, a la fuerza y al azar.

El derecho natural encuentra en la legislación del sistema de protección del consumidor, de forma creciente, regulaciones orientadas hacia el bienestar público general, la justicia y seguridad jurídica. En este sentido, el principio pro consumidor, el derecho a la igualdad de trato o no discriminación, el trato equitativo justo en las relaciones de consumo son algunas de las principales disposiciones inspiradas en el iusnaturalismo. La Constitución como la norma de mayor jerarquía de nuestro sistema jurídico no deja tener vigencia en estos temas; de ahí que sea importante revitalizar la disciplina, sin perder de vista su raigambre constitucional, en cuanto que el consumidor es, en esencia, persona humana, fin supremo de la sociedad y del Estado.

Finalmente, podemos concluir esta parte del artículo con algunas reflexiones que enmarquen el tema propuesto de los derechos humanos del consumidor en el mercado. En ese sentido, hay que decir, en primer lugar, que a nivel mundial existe un tremendo garantismo a favor de los derechos humanos, pero hay que tener en cuenta que existe actualmente un nuevo operador que ha penetrado la escena del derecho internacional público: las organizaciones empresariales transnacionales y los grandes operadores del mercado., Estos se suman a los actores que ya conocíamos: los Estados, las organizaciones internacionales, la Orden Soberana de Malta y el Vaticano.

En la universidad se sigue enseñando, según el canon clásico, que dichos actores son los grandes sujetos del derecho internacional. Esta concepción ha quedado rezagada con el paso del tiempo, porque los nuevos actores que tienen presencia, por su enorme poder económico, en la escena política, social y económica son los que manejan un presupuesto equivalente al de un país: las grandes empresas transnacionales, a las que ya nos referimos.
Estos actores tienen presencia en el mercado, determinan líneas de producción y comportamientos de consumidores y, además, son un eje importante en la escena política y el diseño de las economías de todos los países. El consumidor, cuya esencia - ya dijimos- es la humanidad, se encuentra sujeto a los vaivenes que establezcan estas empresas; está expuesto a lo que establecen arbitrariamente estos operadores de mercado.

No se ha desarrollado un garantismo a favor del consumidor, dirigido hacia el respeto de sus derechos como el protagonista más importante en la escena del mercado y del consumo. Eso, en el fondo, debería ser parte de la defensa de los derechos humanos. Cuando alguien como el Defensor del Pueblo propone una nueva cosmovisión política de la Defensoría del Pueblo con el fin de defender los derechos humanos en el mercado, el establishment, obviamente, reacciona de manera de contraria, a través de críticas a la iniciativa. A propósito, creemos que el discurso del Defensor del Pueblo es acertado y que, además, debería de crearse una adjuntía especializada en derechos del mercado o en la protección de los derechos de la persona en el mercado. Aquello no solo lo sostenemos nosotros, sino otros autores como Ferraloji, Aguilera, López, Alexy, entre otros, que se han aproximado al tema.

Creemos que es necesario que se desarrolle una propuesta política a través de los grandes operadores políticos y públicos del mercado: Defensoría del Pueblo, Tribunal Constitucional, Organismos Reguladores, Agencia de Competencia, entre otros. Estos deben apostar por la defensa de los derechos humanos de las personas en el mercado, porque es en este en el que se materializan aquellos; en el mercado se manifiesta, por ejemplo, el cumplimiento o no de derechos como la educación, la salud, la seguridad, el trato equitativo y justo en las transacciones económicas, etc. El discurso del Defensor del Pueblo es válido, en cuanto hace énfasis en el respeto de estas garantías vitales.

Desde esta palestra proponemos una nueva teoría del garantismo de los derechos humanos o de los derechos de las personas en el mercado, para que estén adecuadamente protegidas; porque así como los derechos a la vida, a la libertad, a la igualdad y a la información cuentan con sus 
respectivas acciones y garantías constitucionales como el hábeas corpus, habeas data y la acción de amparo, entre otras garantías y acciones constitucionales, y todo un desarrollo jurisprudencial y defensa estatal, de la misma manera tiene que haber un desarrollo y garantismo de los derechos del consumidor, persona humana, en el mercado.

\section{La Defensoría del Pueblo y la protección de los derechos del consumidor, bajo la perspectiva constitucional}

Por otra parte, la Defensoría del Pueblo también tiene entre sus finalidades, según el primer párrafo del artículo 162 de la Constitución Política, "supervisar el cumplimiento de los deberes de la administración estatal y la prestación de los servicios públicos a la ciudadanía”. Con ello, está facultada para vigilar a quienes supervisan a las entidades que prestan servicios públicos e incluso a las propias entidades prestadoras. Es por esta razón que consideramos que el Defensor del Pueblo está plenamente autorizado para poder pronunciarse y opinar sobre la protección jurídica de los derechos del consumidor en el Perú, así como para proponer recomendaciones; puede analizar y hacer informes defensoriales sobre la actuación de los llamados organismos tutelares encargados de hacer efectiva la protección de los derechos de los ciudadanos consumidores, con el fin de analizar y opinar con carácter técnico sobre la forma como dichas instituciones, llámense el Instituto Nacional de Defensa de la Competencia y Protección de la Propiedad Intelectual - INDECOPI, la Dirección General de Salud Ambiental - DIGESA, el Instituto Nacional de la Calidad - INACAL, la Superintendencia de Banca, Seguros y AFP - SBS, vienen cumpliendo ese rol, con eficiencia y eficacia, que la ley les ha encomendado por mandato constitucional.

Obviamente hay quienes opinan que la Defensoría del Pueblo no debe ver estos asuntos. Esto es errado, pues, tal como hemos señalado antes, es la propia Constitución la norma que lo faculta. Además, hay que entender que defender los derechos del consumidor es, en esencia, defender a las personas; detrás de cada reclamo, detrás de cada prestación que no se cumplió con satisfacción, hay un drama social y humano y, además, en cada reclamación está la posibilidad de defensa del derecho de la persona, ante una afrenta a su dimensión humana como agente económico en el mercado. En efecto, ¿qué sucede cuando nos tratan mal en los colegios privados? ¿Acaso no está en juego el derecho a la educación? ¿ ¿Qué pasa cuando somos mal atendidos en una clínica privada? ¿Acaso no está en juego nuestro derecho a la salud?5, ¿Qué sucede cuando nos cobran intereses no pactados en un banco o nos cobran una suma indebida? ¿Acaso no está en juego nuestro derecho a la protección de nuestros intereses económicos? ${ }^{6}$ ¿Qué sucede cuando no nos permiten el acceso para ingresar y consumir algo en una discoteca o en un supermercado a causa de la discriminación? ¿Acaso no está en juego nuestro derecho a la

4 Ver resoluciones: Gamarra y Laguna contra Centro Educativo Particular Altair (Resolución 2568-2016/ Sala Especializada en Protección al Consumidor -Indecopi); Comisión de Protección al Consumidor contra Ediciones Magic Book (Resolución 27672013/Sala Especializada en Protección al Consumidor -Indecopi); Heredia y Morón contra Asociación Paola García Medina (Resolución 1629-2017/Sala Especializada en Protección al Consumidor -Indecopi) o Comisión de Protección al Consumidor contra Congregación de los Sagrados Corazones (Resolución 4358-2016/Sala Especializada en Protección al Consumidor -Indecopi).

5 Ver resoluciones: Tapia contra Sociedad Francesa de Beneficencia (Resolución 1386-2006/Tribunal de Defensa de la Competencia-Indecopi) o Jiménez contra Administración de la Clínica Ricardo Palma (Resolución 1337-2005/Tribunal de Defensa de la Competencia-Indecopi).

6 Ver resoluciones: Gonzáles contra Banco de Crédito del Perú (Resolución 0199-2010/Sala de Defensa de la Competencia $\mathrm{N}^{\circ} 2$-Indecopi); Soto contra Banco de Crédito del Perú (Resolución 3122-2015/ sPc-Indecopi); Santos contra Banco de la Microempresa (Mibanco) (Resolución 0256-2012/ Sala de Defensa de la Competencia $\mathrm{N}^{\circ} 2$-Indecopi) o Pinto contra Banco Bilbao Vizcaya Argentaria - BBvA Continental (Resolución 0641-2013/ Sala Especializada en Protección al Consumidor -Indecopi). 
igualdad? ¿ ¿Qué pasa cuando un banco nos envía una agresiva carta de cobranza, simulando ser una notificación juridicial, a nuestro trabajo, a pesar de tener como dirección del préstamo nuestra vivienda? ¿Acaso no está en juego nuestro derecho a la intimidad? ¿Qué sucede cuando se utilizan métodos abusivos de cobranza? ¿Acaso no está en juego nuestra reputación, nuestra privacidad, nuestra imagen frente a los demás? Así podríamos seguir con muchísimos ejemplos. De estos podemos deducir, por lo tanto, que no puede decirse alegremente que son asuntos que pertenecen exclusivamente al mercado. Este reduccionismo desconoce que, en el fondo, lo que está patente en cada reclamación de mercado son necesidades humanas que se defienden.

Decir que la Defensoría del Pueblo no es competente para pedir informes y analizar si la actuación de las instituciones públicas, encargadas de velar por los derechos del consumidor, es idónea, es un razonamiento falaz, porque se piensa que hablar de derechos humanos es solo hablar de personas desplazadas o maltratadas por la violencia terrorista. Sin embargo, hablar de derechos humanos es también hablar de los derechos del consumidor, porque, en el mercado, la persona humana ejerce sus derechos para llevar a cabo su proyecto vital; en el mercado se materializa nuestro derecho a la salud, a la educación, a la igualdad de trato, a la protección de nuestros intereses económicos, a la seguridad, a la intimidad, a la vivienda digna, al agua y saneamiento, etc.

Si no existiera un mercado transparente y competitivo, en el que los operadores de este se

7 Ver resoluciones: Comisión de Protección al Consumidor contra Gesur (Resolución 1415-2006/ Tribunal de Defensa de la Competencia-Indecopi); Comisión de Protección al Consumidor contra Asia Rok (Resolución 18792014/ Sala Especializada en Protección al Consumidor -Indecopi) o Tueros contra Asociación de Manualidades y Arte Creativo (Resolución 3128-2013/ Sala Especializada en Protección al Consumidor -Indecopi).

8 Ver resolución: Comisión de Protección al Consumidor contra Caja Municipal de Ahorro y Crédito del Santa (Resolución 1241-2014/ Sala Especializada en Protección al Consumidor -Indecopi). condujeran con buenas prácticas de atención al cliente, con protocolos de atención y procesos estandarizados de producción, comercialización, venta, despacho y entrega de productos y adecuada prestación de servicios, no podría hablarse, entonces, de la plena satisfacción de los derechos humanos, ya que estos, para poder ser ejercidos en toda su dimensión, necesitan de operadores que permitan que los ciudadanos accedan al mercado y que este les ofrezca diversas formas para satisfacer sus necesidades y, con ello, ejercer sus derechos como persona. Esto significa, entonces, que es en este mercado, en el que la persona humana ejerce sus prerrogativas ciudadanas y sus derechos como consumidor de buena fe. De ahí que sea totalmente lícito que la Defensoría del Pueblo pueda supervisar y pedir cuentas a aquellas instituciones encargadas de supervisar el mercado y, de este modo, hacer que se cumpla ese deber especial de protección, establecido por nuestra Constitución.

En este contexto, cabe señalar que el propio Tribunal Constitucional, en una oportunidad, invocó a los organismos reguladores para que abandonen líneas de pensamiento puramente eficientistas, economicistas y cargadas de una cosmovisión puramente liberal, para así dar paso a una nueva cosmovisión más amplia, que tenga en consideración la real dimensión de los consumidores en el Perú y que piense en ese país diverso que somos.

En efecto, el Tribunal Constitucional, con relación a los organismos reguladores, ha señalado:

A éstos se le ha confiado, entre otras tareas, la defensa de los intereses de los consumidores y usuarios derivados de la prestación del servicio público de telefonía. Como tal, involucra la exigencia de un papel garantista de los intereses y derechos de los consumidores y usuarios de los servicios de telefonía frente a las amenazas o violaciones de los derechos fundamentales que pudieran provenir de los agentes económicos que prestan dicho servicio público. De modo que éste debe y tiene que adoptar todas las medidas necesarias, oportunas y eficaces para contrarrestar apropiadamente las lesiones o amenazas de violación de los derechos de los consumidores y de los usuarios.

$[\ldots]$ 
Es claro que no se puede sostener que el Organismo Supervisor de la Inversión Privada en Telecomunicaciones-OSIPTEL cumpla ese deber especial de protección cuando se adoptan decisiones que manifiestamente repelen un mínimo sentido de justicia material o, en otros términos, cuando tales decisiones aparezcan como manifiestamente irrazonables.

\section{[...]}

en la Sentencia 0976-2001-AA/TC, este Tribunal señaló que los derechos fundamentales también vinculan las relaciones entre privados, de manera que quienes están llamados a resolver controversias que en el seno de esas relaciones se pudieran presentar, han de resolver aquéllas a través de las normas jurídicas que regulan este tipo de relaciones entre privados, pero sin olvidar que los derechos fundamentales no son bienes de libre disposición, y tampoco se encuentran ausentes de las normas que regulan esas relaciones inter privatos.

Antes se ha recordado que uno de los efectos de considerar a los derechos fundamentales como valores materiales del ordenamiento jurídico nacional, es que éstos tienen la propiedad de irradiarse por todo ese ordenamiento.

En tal interpretación de las reglas del derecho privado, el órgano competente no puede perder de vista que, tratándose de negocios jurídicos en los que se insertan determinadas cláusulas generales de contratación, el ejercicio de la libertad contractual y la autonomía privada carece de uno de los presupuestos funcionales de la autonomía privada; particularmente, del sujeto más débil de esa relación contractual. Y es que no se puede afirmar, sin negar la realidad, que, en los convenios suscritos por un individuo aislado, con determinados poderes sociales, o entre personas que tienen una posición de poder económico o de otra índole, existe una relación de simetría e igualdad, presupuesto de la autonomía privada. ${ }^{9}$

Asimismo, se ha criticado muchas veces esa visión purista de carácter económico, que se ha mantenido para resolver algunos conflictos de protección al consumidor, y cuyo alcance social es amplio. En este caso, en efecto,

9 Sentencia del Tribunal Constitucional AI 858-2003. las instituciones tutelares de los derechos de los consumidores han actuado con un papel muy discreto que dista mucho del mandato de deber especial de protección que establece la Constitución.

Según lo expuesto, la Defensoría del Pueblo puede pedir informes a una institución para ver si está adecuadamente organizada operativa y funcionalmente y si puede cumplir con ese deber especial de protección de los consumidores, impuesto por la Constitución. Haciendo un análisis de la actuación de algunas instituciones tutelares en tiempos de crisis del mercado nos podemos dar cuenta que algunas ya se han superado en el tiempo y que su modelo organizacional y funcional para resolver conflictos de consumidor y competencia en el mercado necesita ser reorganizados para dar paso a un sistema más ágil, más orgánico, más sostenido $\mathrm{y}$, fundamentalmente, más vinculado al contexto real del mercado. Es decir, hay instituciones que necesitan ser reorganizadas y hacer una revisión seria de sus procesos para ver si están funcionando conforme a las exigencias del mercado actual; ya no estamos en los años noventa, esa época de aprendizaje primario de una cultura de mercado.

Hoy, veinticinco años después, instituciones como el Instituto Nacional de Defensa de la Competencia y Protección del Consumidor (Indecopi), la Superintendencia de Banca, Seguros y AFP(SBS), el Instituto Nacional de Calidad (Inacal), los organismos reguladores, entre otros, necesitan con urgencia crear imágenes y motivaciones nuevas a la sociedad, que generen mayor confiabilidad en el sistema de protección de los consumidores y respeto a las reglas del mercado, con transparencia y competitividad. En este sentido, la Defensoría puede ser la institución que haga un informe al respecto y pueda promover, en dichas instituciones, los cambios de visión y de líneas de pensamiento jurídico innovadoras, para crear un sistema de mercado saludable, un sistema de protección eficiente y, en general, una reingeniería para responder de mejor manera a las demandas ciudadanas de un pueblo de consumidores. Hay que tener en cuenta que este pueblo 
demanda, además, de sus instituciones tutelares un rol más activo, más cercano al ciudadano, más enraizado en la esencia misma de la gente; instituciones capaces de entender a los consumidores y las angustias desencadenadas por un mercado en el que muchos de sus operadores no actúan necesariamente dentro de un marco eficiente $y$, en algunos casos, ético.

Esta propuesta obviamente no es popular y no suele ser asumida amablemente por un gran sector de juristas o analistas de mercado, que siguen pensando que el Perú de los años noventa es igual al actual. No obstante, hoy estamos en otra dimensión del mercado: tenemos más empresas y cada vez más grandes, más operadores, una economía creciente, consumidores más informados y empoderados, instituciones más sólidas y con mayor experiencia y cultura en materia de mercado, consumo y competencia. Por esto, el mercado y los consumidores demandan ya un cambio de visión en algunas de las instituciones tutelares, llamadas a sancionar las malas conductas de los operadores y llamadas también a crear una cultura de consumo responsable para todos los actores del mercado, así como a promover un desarrollo del mercado con buenas prácticas y con líneas de responsabilidad social empresarial, en las que la principal obligación sea satisfacer las necesidades de los consumidores con productos y servicios de calidad.

En virtud de lo expuesto, la Defensoría sí puede estudiar y analizar si las instituciones tutelares del mercado están cumpliendo adecuadamente su rol y si su organización funcional y administrativa responde a las exigencias de un mercado como el de hoy en el Perú, lleno de presiones crecientes y extendidas. Esto ha debido hacerlo desde hace tiempo, pues su omisión ha permitido que se sigan resolviendo los conflictos de consumo y competencia con una cosmovisión rezagada, que responde a un modelo organizacional desfasado y descontextualizado de la realidad del mercado peruano. La causa tentativa es que la Defensoría ha tenido una visión unidimensional de los derechos humanos, dado que los vincula solo a personas indocumentadas, desplazadas, discriminadas o afectadas por la violencia terrorista, entre otros, y no ha tenido una visión sistémica, holística y multidimensional de los derechos humanos, que los entienda como prerrogativas de la persona en toda su extensión. Este problema se ha presentado, a pesar de que nuestra Constitución establece todo un conjunto de derechos y prerrogativas que los peruanos tenemos como personas. En este contexto, no se tuvo en cuenta la dimensión económica de los individuos, que es también importante en cuanto tenemos derecho a la protección de nuestros intereses en ese ámbito. Por esta razón, el Estado debería garantizar que haya una dinámica mercantil en la que se respeten las reglas del mercado y los derechos de los consumidores.

El discurso del actual Defensor del Pueblo (Dr. Walter Gutiérrez Camacho) es coherente y sistémico y, en ese sentido, es preciso tener cuidado de no generar resoluciones contradictorias entre las instituciones creadas para proteger al consumidor; es importante, más bien, generar confiabilidad y predictibilidad en el sistema y no bloquear el desarrollo y la iniciativa empresarial por disposiciones que, lejos de promover la protección, terminan afectando el mercado (Durand, 2011, p. 64).

En este panorama opinamos que incluso la Defensoría debería reestructurarse y hacer una reorganización administrativa para adecuar mejor su configuración actual a los nuevos retos y desafíos que le impone una visión renovadora de su función. De ese modo, podría crear una adjuntía especializada en la protección de los derechos de las personas en el mercado, que complemente su actual trabajo en esta materia. Ello tendría una lógica sistémica, porque en el mercado se materializan los derechos humanos de los ciudadanos consumidores; en ese espacio se puede evidenciar si se respeta la condición intrínseca que los consumidores tienen como seres humanos. No olvidemos que detrás de cada denuncia de protección al consumidor hay una demanda insatisfecha a una necesidad humana y detrás de cada reclamo hay una drama social y humano que es preciso atender. Eso, en esencia, tiene una naturaleza de derechos humanos que no se puede negar ni discutir. 


\section{Órganos estatales y deber especial de protección de los derechos del consumidor por mandato constitucional}

El tema señalado anteriormente es muy claro, tanto que el propio Tribunal Constitucional ha establecido que, detrás de cada reclamo de consumo, existe una manifiesta violación del "deber especial de protección" de los derechos fundamentales que repercute directamente en el derecho constitucional a la protección de los usuarios y consumidores, reconocido en el artículo 65 de la Constitución Política del Perú.

Debido a la influencia de diversas teorías que han servido de base al constitucionalismo moderno, el Estado ha sido instituido al servicio de los derechos fundamentales. El Estado, en efecto, tiene en relación con los derechos fundamentales un “deber especial de protección”, lo cual no es solo una cuestión teorética derivada de la existencia de una o más teorías sobre la legitimidad del Estado. Esto significa que en el ordenamiento constitucional peruano todas las leyes, reglamentos y sus actos de aplicación deben interpretarse y aplicarse de conformidad con los derechos fundamentales

En ese sentido, la constitucionalización del "deber especial de protección" representa una exigencia sobre todos los órganos del Estado: se deben proteger, por diversas vías, los derechos fundamentales, ya sea cuando estos han sido puestos en peligro por actos de particulares o cuando su lesión se derive de otros Estados. Se trata de una función que debe asumir el Estado, a través de sus órganos, cuando los derechos y libertades fundamentales pudieran resultar lesionados en aquellas zonas del ordenamiento en las que las relaciones jurídicas se entablan entre sujetos que tradicionalmente no son los destinatarios normales de esos derechos fundamentales. En este contexto debe ser entendida la función del Defensor del Pueblo en materia de derecho del consumidor.

En el ámbito de los usuarios y consumidores, ese deber especial de protección se encuentra establecido expresamente en el artículo 65 de la Constitución. Dicho precepto constitucional establece:
El Estado defiende el interés de los consumidores y usuarios. Para tal efecto, garantiza "el derecho a la información sobre los bienes y servicios que se encuentran a su disposición en el mercado", así como vela, "en particular, por la salud y la seguridad de la población”.

En los fundamentos jurídicos, Número 27, y los siguientes de la Sentencia 0008-2003-AI/TC, el Tribunal Constitucional sostuvo ${ }^{10}$ :

Así como la Constitución protege a los agentes económicos encargados de establecer la oferta en el mercado, a partir del ejercicio de los derechos de libre empresa, comercio e industria, con igual énfasis protege al individuo generador de demanda, es decir, al consumidor o el usuario.

El consumidor -o usuario- es el fin de toda actividad económica; es decir, es quien cierra el círculo económico satisfaciendo sus necesidades y acrecentando su bienestar a través de la utilización de una gama de productos y servicios. En puridad, se trata de una persona natural o jurídica que adquiere, utiliza o disfruta de determinados productos [como consumidor] o servicios [como usuario] que previamente han sido ofrecidos al mercado.

Es indudable que la condición de consumidor o usuario se produce a través de la relación que éste entabla con un agente proveedor -independientemente de su carácter público o privado-, sea en calidad de receptor o beneficiario de algún producto, sea en calidad de destinatario de alguna forma de servicio.

En consecuencia, la condición de consumidor o usuario no es asignable a cualquier individuo o ente, sino a aquel vinculado a los agentes proveedores dentro del contexto de las relaciones generadas por el mercado, las cuales tienen como correlato la actuación del Estado para garantizar su correcto desenvolvimiento.

[...]

La Constitución prescribe en su artículo 65 la defensa de los intereses de los consumidores y usuarios, a través de un derrotero jurídico binario; vale

10 Sentencia del Tribunal Constitucional: sentencia 0008-2003-AI/TC. 
decir, establece un principio rector para la actuación del Estado y, simultáneamente, consagra un derecho subjetivo. En cuanto a lo primero, el artículo tiene la dimensión de una pauta básica o postulado destinado a orientar y fundamentar la actuación del Estado respecto a cualquier actividad económica. Así, el juicio estimativo y el juicio lógico derivado de la conducta del Estado sobre la materia tienen como horizonte tuitivo la defensa de los intereses de los consumidores y los usuarios. En cuanto a lo segundo, la Constitución reconoce el derecho de defenderse de los consumidores y usuarios en los casos de transgresión o desconocimiento de sus legítimos intereses; es decir, reconoce el derecho de exigir al Estado una actuación determinada cuando se produzca alguna forma de amenaza o afectación efectiva de los derechos de consumidor o usuario, incluyendo la capacidad de acción contra el propio proveedor.

En la misma resolución el Tribunal ha sostenido:

De acuerdo con lo establecido por el artículo 65 de la Constitución, el Estado mantiene con los consumidores o usuarios dos obligaciones genéricas; a saber:

a) Garantiza el derecho a la información sobre los bienes y servicios que estén a su disposición en el mercado. Ello implica la consignación de datos veraces, suficientes, apropiados y fácilmente accesibles.

b) Vela por la salud y la seguridad de las personas en su condición de consumidoras o usuarias.

A pesar de que existe un reconocimiento expreso del derecho a la información y a la protección de la salud y la seguridad de los consumidores o usuarios, estos no son los únicos que traducen la real dimensión de la defensa y tuitividad consagrada en la Constitución. Es esta se puede apreciar una pluralidad de situaciones que son genéricas en su naturaleza, incorporadas en el mismo texto fundamental, y que suponen un numerus apertus a otras expresiones sucedáneas.

Con tal premisa, señala la resolución del Tribunal Constitucional:

el propio Estado, a través de la Ley de Protección al Consumidor y el posterior Código de Protección y Defensa del Consumidor, no sólo ha regulado los derechos vinculados a la información, salud y seguridad, sino que ha comprendido a otros de naturaleza análoga para los fines que contrae el artículo 65 de la Constitución. Por ello, los derechos de acceso al mercado, a la protección de los intereses económicos, a la reparación por daños y perjuicios y a la defensa corporativa del consumidor, se erigen también en derechos fundamentales reconocidos a los consumidores y usuarios [...].

De ahí que el Tribunal Constitucional no considere que el ámbito de protección constitucional de los derechos de los consumidores y usuarios se traduzca sólo en garantizar que los órganos administrativos presten una adecuada garantía al "derecho a la información sobre los bienes y servicios que se encuentran a su disposición en el mercado”, o en velar "[...] en particular, por la salud y la seguridad de la población".

Por ello, a juicio del Tribunal Constitucional, la primera parte del artículo 65 de la Constitución contiene un genérico deber especial de protección del consumidor y el usuario que asume el Estado, cuyas formas se traducen solo de manera enunciativa en garantizar "el derecho a la información sobre los bienes y servicios que se encuentran a su disposición en el mercado", así como en velar, "en particular, por la salud y la seguridad de la población".

Existen una serie de deberes impuestos al Estado, en el artículo 65 de la Constitución, y corresponden a una serie de exigencias que recaen sobre diversos órganos de este. En primer lugar, sobre el legislador ordinario, al que se le impone la tarea, mediante la legislación, de crear un órgano estatal destinado a preservar los derechos e intereses legítimos de los consumidores y usuarios, así como también la tarea de establecer procedimientos apropiados para que, en su seno, los consumidores y usuarios puedan, mediante recursos sencillos, rápidos y efectivos, solicitar la protección de aquellos derechos e intereses, a través de procedimientos céleres y sensatos. Esto es, en síntesis, el garantismo constitucional de los derechos de los consumidores que, a través de este artículo, proponemos. Para ello, dejamos de lado interpretaciones restrictivas que, eventualmente, han formado parte del ideario resolutivo de algunos órganos colegiados 
de organismos reguladores y del propio Indecopi. A propósito de esto, hay que reconocer que incluso el propio Tribunal Constitucional, a través de diversas resoluciones, llama la atención sobre este tema y establece criterios para que dichos órganos adecuen sus decisiones a una mirada mucho más real, sistémica y contextual en materia de protección de los intereses de los consumidores y usuarios, establecidos por mandato constitucional.

\section{El Estado como proveedor de servicios en una relación de consumo}

El Estado concebido jurídicamente como el cuerpo político de una Nación o como la organización política y jurídica de la sociedad, dotada de poder respecto a un territorio determinado; es por antonomasia un "prestador de servicios públicos", pues los administrados, precisamente, han delegado en él el fomento y la prestación eficiente y responsable de una serie de servicios de carácter social amplio.

Desde la época de Aristóteles hasta los planteamientos iusnaturalistas se ha determinado que la causa final del Estado es el "bien común", o sea, el "bien a la comunidad". Esta es una verdad firme y universal por la que todo Estado debe luchar, independientemente del esquema ideológico en que se sustente. Aristóteles, de hecho, señalaba que el hombre se congrega en sociedad no para el bien de uno, sino para el bien de todos en sentido comunitario.

Se define el bien común como el conjunto de condiciones sociales que favorecen la existencia y el desarrollo del hombre. Este determina el medio social propicio para que la persona se realice. No es una masa de bienes por repartir, sino un orden justo, más allá del cual existe para el individuo un fin último. El bien común se puede compartir, porque todos cooperan; es redistribuible, porque redunda en beneficio de todos, y jerárquico, pues ocupa una posición superior a los bienes del hombre y del Estado. Expresa que la consecución del bien particular es favorecida o flanqueada por la existencia de un orden que brinda seguridad y justicia, a través de los servicios públicos (Ferrero, 1984).
El bien común centra la vida de la comunidad política, anima la actividad del gobierno y da sentido a la ley como instrumento de acción. Tal definición del bien común como el medio social propicio para que el hombre realice sus potencialidades, a decir de Santo Tomás de Aquino, es individualista, por ello hay que sobreponerle la concepción comunitaria: el bien común es un orden justo para la vida suficiente de una comunidad. Tiene el carácter de bien intermedio para hacer alcanzable el bien individual y familiar.

Si se despoja la idea del bien común de su connotación filosófica, esta se convertiría en lo que llamamos "interés social". El bien común no es fórmula de gobierno, sino un principio rector. Por eso, Dabin lo denomina "bien común público", para expresar, mediante el uso de la palabra "público", que este engloba bienes sociales considerados indispensables para el bien individual, como la seguridad de la vida y la de poseer el fruto del trabajo, la educación, el matrimonio, los servicios de salud, los medios de transporte masivo, la vivienda, etc.

Ahora bien, otro de los dogmas clásicos de la teoría del Estado es la "separación de poderes", que pertenece al bagaje estándar del Estado constitucional desarrollado por Montesquieu y que surge para el cumplimiento de los roles de aquel. Pero lo que, en realidad, implica la separación de poderes es el reconocimiento de que el Estado tiene que cumplir determinadas funciones. La libertad es el telón ideológico de la teoría de la separación de poderes, que no es sino la forma clásica de distribuir y controlar el ejercicio del poder político. Lo que corrientemente, aunque erróneamente, se suele designar como la separación de los poderes estatales es, en realidad, la distribución de determinadas funciones estatales a diferentes órganos del Estado (Loewenstein, 1993).

El concepto de "poderes", pese a lo profundamente enraizado que está, debe ser entendido en este contexto de una manera meramente figurativa. De ahí que Loewenstein habla en su obra de "separación de funciones", que obviamente es la búsqueda del bien común.

Posteriormente, en la segunda década del siglo pasado, la Constitución Mexicana de Querétaro 
(1917) y la Constitución Alemana de Weimar (1919) desarrollan los principios del llamado "constitucionalismo social", a través de fórmulas nuevas sobre el interés social que revolucionaron los esquemas políticos de la época y que recogieron después casi todos los ordenamientos jurídicos. El Estado asume con esta teoría nuevos roles y funciones de carácter social más amplio, con una cobertura más completa. Luego, la crisis del año 1929 reformuló las líneas de un intervencionismo estatal más creciente.

Hoy, a la luz del mundo moderno de la globalización económica y de la apertura de mercados, de la desaparición de fronteras, de la pacificación, etc., el Estado ha redefinido su esquema de división de funciones, según la exigencia que los cambios socioeconómicos le imponen. Por este motivo, asume hoy un nuevo rol en la búsqueda del bien común, fijando nuevas reglas del juego económico.

En este contexto, las normas jurídicas que regulan la prestación de servicios públicos han sido modificadas para brindar mayor eficiencia, celeridad, calidad y, sobre todo, mejor cobertura y alcance social. Por lo tanto, con relación a las reglas del mercado, el Estado moderno debe interactuar con otros grupos y fuerzas que al manifestarse adquieren un peso político, ya que poseen un grado de influencia original distinto de él. Para no seguir con el desencanto colectivo de la sociedad, que espera aún la consecución del bien común, es necesario tener en cuenta los desafiantes y sugestivos trabajos de Coase y de Posner y los planteamientos del Law and Economics que, al margen de sus posiciones filosófico-sociales y del frío análisis económico, toman en cuenta el funcionamiento económico de las instituciones del Derecho. (De Trazegnies, 1996).

En este contexto, el Estado peruano, en materia de servicio público, ha llevado a cabo innovaciones normativas, impulsadas por la doctrina moderna llamada "Desregulación de servicios públicos". Más adelante haremos énfasis en este punto.

\section{El Estado, proveedor de servicios}

La prestación de servicios públicos constituye una de las características más prominentes en la estructura del Estado moderno. La intervención estatal, en este sentido, es amplia, pues abarca aspectos tan amplios y diversos como seguridad social, educación, cultura, recreación, deportes, tutela jurisdiccional, orden interno, entre otros. De ahí que la participación en el mercado sea un aspecto importante para el aparato estatal.

Por otra parte, existen elementos del Estado que pertenecen a una misma categoría o nivel de importancia y que, de una u otra manera, determinan ciertas características en la forma como aquel presta los servicios públicos. En efecto, la tradición e idiosincrasia, el territorio, el aparato administrativo, el poder soberano, el orden económico, político y jurídico, entre otros elementos similares y complementarios influyen en la forma en la que el Estado establece las regulaciones del mercado, a fin de corregir las distorsiones que pueden afectar los grandes objetivos nacionales.

El Estado peruano ha hecho, en los últimos años, varios ensayos con el fin de encontrar la organización administrativa más adecuada para prestar servicios públicos: por ejemplo, ha privatizado algunas empresas públicas; ha facilitado el acceso y la concurrencia del sector privado en la prestación de servicios públicos, antes reservada solo a lo estatal, sin afectar el beneficio a los ciudadanos, y ha aplicado severos procesos de reingeniería en algunas instituciones públicas (como el Indecopi, La Sunarp, Sunat, etc.). Es obvio que todos estos cambios operados por el Estado han sido acompañados de la correspondiente legislación, que ha dado el soporte necesario para asumir los retos que implica prestar un servicio público. Quizá uno de los hechos más importantes del Estado, en este contexto, es la desregulación de los servicios públicos, que ahora son prestados por empresas privadas y la creación de organismos reguladores de la prestación de dichos servicios públicos, como es el caso de Osiptel, Sunass, Osinergmin, Ositran.

La visión del Estado moderno como "prestador de servicios" exige una nueva cosmovisión en materia de servicio público, en la que la indefensión y el oscurantismo que tiene la dictadura de la ventanilla y del escritorio (de la que hablaba Ribeyro), de la que es presa hoy el ciudadano, sea superada por un servicio con valor agregado, 
capaz de acercarse al ciudadano. Se trataría, además, de un servicio sostenido en la transparencia, la eficiencia y la celeridad. Esta nueva visión, que todos esperamos actualmente de un Estado, implica una ardua tarea que debe pasar por una redefinición de la misión, la visión y de los valores de la burocracia moderna. Se deben crear nuevas estructuras de decisión administrativa y de gestión pública, para evitar la insatisfacción del ciudadano consumidor, que espera siempre inmediatez, eficiencia, eficacia, simplicidad, calidad del servicio, atención personalizada, etc.

Esta nueva cosmovisión del servicio público traerá consigo el establecimiento de nuevas relaciones de confianza entre el Estado y el consumidor. Para ello, el primero debe ser capaz de observar, desde un punto de vista integral, lo que significa un servicio público y hacer lo que cualquier prestador de servicios hace: ver que quiere el cliente, tabular una matriz de resultados y crear productos para satisfacer las necesidades ciudadanas; además, no debe temer al reclamo, ya que la cultura de este incentiva las mejoras, la creatividad y la innovación en la prestación de los servicios de una sociedad.

Lo que se podría hacer al respecto es, por ejemplo, dar mayor acceso a los servicios estatales de solución de conflictos; promover una mayor sinergia entre las instituciones relacionadas con la prestación de los servicios públicos; orientar al consumidor; informar a los consumidores sobre sus derechos; crear procedimientos estandarizados (procedimientos paper less); obtener y tabular estadísticas de gestión pública para retroalimentación, y tener una visión integral de los problemas ciudadanos, etc. Si el Estado no es capaz de crear una nueva cultura como prestador de servicios públicos, los ciudadanos en cuantos consumidores subvertirán el orden y buscarían evadirla burocracia para obtener un sistema de gestión y mejor atención al público.

Si el Estado no hace nada por acercarse al ciudadano, entonces, es en sí mismo un fracaso El servicio público en cualquiera de sus grados es una función de la administración del Estado, dirigido a la satisfacción de una necesidad pública, como un proceso técnico prestacional. El signo de esta época es la multiplicación de los servicios públicos, consecuencia de las tendencias políticas de orden social que predominan en los Estados modernos. A propósito, podríamos tener en cuenta la visión de Guillermo Cabanellas (1981), que define que un "concepto capital del Derecho Político y del Derecho Administrativo es éste del servicio público, que ha de satisfacer una necesidad colectiva por medio de una organización administrativa o regida por la Administración Pública” (pp. 396-397).

La noción de servicio público se ha intentado perfilar y precisar sin resultados satisfactorios, incluso desde la constitución misma del Estado moderno; aún en nuestros tiempos es un concepto impreciso, cuyas definiciones son tan variadas como los autores se han ocupado de este (Dromi, 1985).

Dromi (1985) que, sistematizando una interpretación positiva, tenemos el siguiente esquema:

1. Máxima: servicio público es toda actividad del Estado, cuyo cumplimiento debe ser asegurado, regulado y controlado.

2. Media: servicio público es toda la actividad de la administración pública.

3. Mínima: servicio público es una parte de la actividad administrativa.

Además, el servicio público tiene un régimen especial que implica una triada de elementos:

1. Fin que cumple: satisfacer una necesidad pública colectiva. interés público.

2. Organización que lo presta: administración pública directa o indirecta.

3. Forma o régimen jurídico que lo regula: público.

Boquera (1972) desdobla las diversas acepciones que el concepto de servicio público ha merecido. Así, para unos autores, 'servicio' es una organización de medios y para otros una actividad o función estatal. En cuanto al término 'público', las tendencias doctrinales se dividen de acuerdo con lo siguiente: la condición del sujeto titular (personas públicas); el fin del servicio (público); el régimen jurídico al que se somete (derecho público), y los destinatarios o usuarios (el público) (p. 211). 
Los servicios públicos como dato sociológico de la actividad pública prestacional son subsumidos en las funciones del Estado. El servicio público es la prestación realizada por la administración pública activa, directa o indirectamente, para la satisfacción concreta de necesidades colectivas; dicha prestación es asegurada por el poder de la policía (Bielsa, 1964). Quiere decir, entonces, que el hecho de que algunos servicios públicos puedan ser eventualmente prestados por particulares, debidamente autorizados por el Estado, no borra la naturaleza jurídica de lo público; tal es el caso de la educación.

\section{Relación de consumo: Estado-ciudadano consumidor}

El hombre es sujeto de necesidades desde su nacimiento y, por ende, es consumidor individual o colectivamente con sus pares. Como ya lo hemos señalado anteriormente, el Estado debe reconocerse, a su vez, como un prestador de servicios que establece frente a los ciudadanos una "relación de consumo"; en este vínculo, las personas tienen la condición jurídica de consumidor y pueden exigir al Estado el cumplimiento de sus obligaciones de servicio. De ahí que este deba cumplir los estándares mínimos de calidad, eficiencia, celeridad, bajos costos sociales y económicos que se esperan y se exigen a cualquier proveedor. Por eso es importante que la organización administrativa por la que opte el Estado para prestar un servicio sea ágil y adecuada. Aquella relación de consumo es una relación viva, dinámica, fluida, que implica una retroalimentación de información para lograr la eficiencia y calidad en los servicios públicos y deja al descubierto la concepción clásica, rigorista y formal que implicaba antes una relación con el Estado, basada en criterios de rigidez administrativa entre este y los particulares. Hoy el fenómeno de colaboración entre los particulares y el Estado es intenso y se desarrolla a través de diversas formas.

En la realidad social concurren y se polarizan una serie de vinculaciones o relaciones interindividuales: unos con otros se relacionan para satisfacer necesidades o para equilibrar sus intereses con los de los demás. Esta es la relación de consumo entre Estado y administrados, en la que hay de por medio una materia con determinación jurídica: el servicio público (Savigni, 1978).

\section{El nuevo concepto de servicio público}

Desde su aparición en la jurisprudencia y la doctrina francesa del siglo XIX, la noción de servicio público dista mucho de ser pacífica y de ser unánimemente admitida por todos con un contenido idéntico. No se trata ahora de reproducir la vieja polémica entre Duguit y Haoriou sobre el sentido del servicio público, pero no por ello se debe dejar de señalar que, si en un principio el concepto había surgido para justificar la necesidad de la actuación de la administración pública en determinados sectores a los que no llegaba el libre funcionamiento del mercado, 'servicio público' ha sido objeto de una ampliación teorética. En buena medida, como consecuencia de esa ampliación, se ha podido considerar que el sistema natural de prestación de los servicios públicos lo constituía el régimen de monopolio.

Como reacción a esa ampliación del concepto de servicio público surge en los textos de la Comunidad Europea, a partir de 1987, el concepto de 'objetivo del servicio universal'. Este nuevo concepto viene a significar dos extremos: en primer lugar, un servicio de base que ha de ser ofrecido al conjunto de los ciudadanos, a condiciones tarifarias asequibles y con un nivel de calidad estándar y, en segundo lugar, una obligación que se impone a los operadores en régimen de concurrencia, para que el libre juego del mercado no se dedique a prestar exclusivamente los servicios en aquellas condiciones en las que sea rentable, dejando al margen a importantes sectores de los ciudadanos (Consejo de Estado, 1995).

Como puede fácilmente comprenderse, el concepto de servicio universal ni supone un concepto antagónico al de servicio público ni tampoco un cambio radical en los efectos sociales de los servicios, sino que viene a poner el acento en el régimen de prestación de los servicios. El nuevo concepto precisa de un cambio en la regulación de los servicios públicos, cuyos límites no están perfectamente 
delimitados. Como ha señalado acertadamente Ariño (1997):

El cambio esencialmente consiste en el paso de un sistema de titularidad pública sobre la actividad, concesiones cerradas, derechos de exclusiva, obligación de suministro, precios administrativamente fijados, carácter temporal (con reversión/rescate en todo caso) y regulación total de la actividad hasta el más mínimo detalle, a un sistema abierto, presidido por la libertad de empresa, esto es, libertad de entrada (previa autorización reglada), con determinadas obligaciones o cargas de 'servicio universal', pero con libertad de inversión y amortización y, en definitiva, en régimen de competencia abierta, como cualquier otra actividad comercial o industrial, en la que hay que luchar por el cliente (no hay mercados reservados ni ciudadanos cautivos). (p. 25)

Es necesario concluir que la nueva concepción de servicio público ha de considerarse fundamentalmente unida al concepto de prestación de servicios en régimen de competencia $\mathrm{y}$, sobre todo, como una imposición dirigida a quien ha de prestar tales servicios, pero no como una pérdida de los beneficios sociales.

Es verdad que, en cierta medida, el concepto de servicio universal va unido a una cierta disminución del tamaño del servicio que se presta, pero al fin y al cabo no hay que olvidar que el alcance y tamaño del servicio constituye una opción propia de la gestión administrativa y que siempre se va a tender a ampliar el servicio. Diferentes opciones políticas pueden significar dimensiones diferentes y ello será particularmente significativo en los servicios públicos de contenido social, tales como la sanidad o la educación.

En los últimos tiempos hay una opinión generalizada: la competencia es uno de los motores del crecimiento económico, la eficiencia económica, la integración de mercados y la creciente protección de los derechos del consumidor. De esta afirmación se deduce la apertura al debate de determinadas cuestiones, como las relativas al papel de las empresas públicas, la revisión del concepto de servicio público, las privatizaciones o el alcance de la regulación.
Antonio Creus, en una exposición desarrollada en el Seminario Internacional sobre Políticas de Competencia y Consumidor, llevada a cabo en Lima del 25 al 29 de mayo de 1998 con ocasión del V Aniversario de Indecopi, expresó que la nueva connotación del servicio público y la protección de los derechos del consumidor incluye hoy un conjunto de obligaciones que antes eran prestadas únicamente por un operador dominante (el Estado) y que ahora son cumplidas también por un operador que reúna determinados requisitos. Esta prestación debe asegurar el acceso a todos los usuarios a un servicio de calidad y a precios asequibles, sin ningún tipo de discriminación.

En la Comunidad Europea no se prejuzga el carácter privado o público de las entidades encargadas de ofrecer servicios públicos y no exige ninguna privatización. Los comportamientos anticompetitivos de estos entes son controlados por la Comisión Europea, independientemente del estatuto público o privado de las empresas. Para analizar el panorama actual de los servicios públicos en la Unión Europea, es importante remitirse a la Comunicación de la Comisión publicada en 1996: "Los servicios de interés general en Europa" (Diario Oficial de las Comunidades Europeas, 1996). En ella, la Comisión hace hincapié en la necesidad de buscar un equilibrio entre el fortalecimiento del mercado interior, basado en la libre competencia, la protección del consumidor y la subsistencia de los servicios públicos. La introducción del mercado sin fronteras y el desarrollo de nuevas tecnologías representan un nuevo reto para los operadores del mercado y concesionarios de los servicios públicos, así como para los tradicionales monopolios del Estado que se ven obligados a mejorar la oferta, la calidad y a bajar los precios para hacer frente a la aparición de nuevos operadores en el mercado.

\section{A manera de conclusión}

A lo largo del presente artículo nos hemos aproximado a una teoría de los derechos de las personas, a través de la construcción jurídica de los derechos humanos del consumidor en el mercado; este objetivo nos ha llevado a estudiar y analizar el derecho 
del consumidor desde una perspectiva real, que tenga en cuenta las dinámicas de hoy.

En estas páginas, hemos plasmado la concepción humanista de los derechos del consumidor, con el fin de observar su desarrollo doctrinal y jurisprudencial a partir de su propia naturaleza jurídica, es decir, a partir de la ontología misma de su autonomía y su vigencia, como una de las disciplinas jurídicas más relevantes del derecho en el siglo XXI. El propósito es, en ese sentido, alcanzar un verdadero estándar jurídico en el respeto y la valoración de los derechos de las personas en el mercado, algo que, en la actualidad, prácticamente no ocurre.

Entendemos que el consumidor, en cuanto ser humano, es un agente del mercado complejo y cambiante, y que el devenir de su actividad mercantil es una sumatoria de decisiones que tienden a la búsqueda de la satisfacción de sus intereses y expectativas personales, pero, sobre todo, es un requerimiento cuasi obligatorio para cumplir con la satisfacción plena de sus necesidades, condición que, eventualmente, termina por fundamentar su propia dignidad.

En este sentido, la escena jurídica mundial nos permite identificar una serie de prerrogativas, condiciones y fundamentos iusfilosóficos que, a su vez, constituyen pilares para construir un nuevo paradigma que potencie la teoría de los derechos humanos, relacionada esta vez con el desenvolvimiento del consumidor en el propio mercado. Esto sobrentiende que los consumidores son en esencia personas que acuden al mercado con el fin de satisfacer sus necesidades.

Debemos señalar que la relevancia y permanencia del mercado es tan grande que, mientras comenzamos a proponer nuevas soluciones a todo lo que observamos en la realidad, en las innumerables relaciones de consumo que se celebran día a día ya se han comenzado a generar nuevos problemas, propios de la dinámica mercantil de un mercado como el de hoy: lleno de presiones crecientes y extendidas. Por ello, los juristas no podemos negar ni discutir, sino proponer nuevos enfoques jurídicos para resolver estos problemas actuales.

Finalmente, el resumen de las ideas y el contenido del artículo deja ver que aún queda un largo camino por recorrer en nuestra disciplina y más aún en países como el Perú, donde todavía se carece de institucionalidad, de precisión, de coherencia normativa y de trabajo articulado por parte de los organismos competentes en la protección al consumidor. Así mismo, debemos reafirmar nuestra postura, pues es momento para pensar el derecho del consumidor desde otras perspectivas que hagan efectiva su evolución y desarrollo; para ello, también es necesario que las instituciones puedan ser afines a nuestra realidad e integren de manera inteligente una propuesta normativa que beneficie no solo a los consumidores, sino también a los empresarios. De esta manera, se cumplirá con el fin fundamental de la propia norma: servir como herramienta al ser humano para que este pueda realizarse. Aquello exige, a su vez, no perder de vista que el derecho es también un factor de desarrollo social y económico, cuya articulación adecuada permite obtener beneficios a todos los actores de la escena pública, es decir, al Estado, los consumidores y los propios operadores de mercado. Nos queda mucho camino por recorrer, pero siempre es bueno dar los primeros pasos.

\section{Referencias}

Aguilera, R. y López, R. (2011). Los derechos fundamentales en la teoría garantista de Luigi Ferraloji. En Nuevas perspectivas y desafíos en la protección de los derechos humanos. Serie Estudios Jurídicos. Ciudad de México: Editorial Unam.

Alexy, R. (2002). Teoría de los derechos fundamentales (E. G. Valdés, trad.). Madrid: CEPC.

Ariño, G. (1997). Sobre el significado actual de la noción de servicio público y su régimen jurídico. (Hacia un modelo de regulación). En El nuevo servicio público. Madrid: Editorial Marcial Pons.

Bielsa, R. (1964). Derecho administrativo (6.a ed.). Buenos Aires: Editorial Ciudad Argentina.

Boquera, J. (1972). Derecho administrativo. Volumen I. Madrid: Editorial IEAL.

Cabanellas, G. (1981). Diccionario enciclopédico de derecho usual (18.a ed.). Tomo vII. Buenos Aires: Editorial Heliasta SRL.

De Trazegnies, F. Prólogo. En A. S. Ríos, Introducción a la juseconomía. Lima: Fondo Editorial PUCP. 
Dromi, J. (1985). Derecho administrativo económico. Tomo II. Buenos Aires: Editorial Astrea.

Durand, J. (2011). El verdadero alcance normativo de la Legislación de Competencia frente a los Derechos del Consumidor. Revista Círculo de Derecho Administrativo, (10). Lima: Editorial PUCP.

EUR-Lex. (1996). Comunicación de la Comisión. Los servicios de interés general en Europa [Diario Oficial C 281 de 26.9.1996]. Recuperado de https://eur-lex.europa. eu/legal-content/ES/TXT/?uri=LEGISSUM\%3Al26087

Farina, J. (1995). Defensa del consumidor y del usuario. Buenos Aires: Editorial Astrea.

Ferrajoli, L. (1998). Derecho y razón. Teoría del garantismo penal. Madrid: Editorial Trotta.

Ferrajoli, L. (1999). Los fundamentos de los derechos fundamentales. Madrid: Editorial Trotta.

Ferrajoli, L. (2004a). Expectativas y garantías. En Epistemología jurídica y garantismo. Ciudad de México: Editorial Fontamara.
Ferrajoli, L. (2004b). La semántica de la teoría del derecho. En Epistemología jurídica y garantismo. Ciudad de México, México: Editorial Fontamara.

Ferrero, R. (1984). Ciencia política (7. a ed.). Lima: Editorial Ausonia.

Guastini, R. (1999). Tarello: la filosofía del derecho como metajurisprudencia. En Distinguiendo (estudios de teoría y metateoría del derecho). Barcelona: Editorial Gedisa.

Loewenstein, K. (1993). Teoría de la constitución. Barcelona: Editorial Ariel Demos.

Rubio, M. (1999). Estudio de la Constitución Política del Perú de 1993. Lima: Fondo Editorial PucP.

Savigny, F. (1978). De la vocación de nuestro siglo para la legislación y la ciencia del derecho. Tratado de Adolfo Posada. Valparaíso: Editorial Edevakl.

Torres y Torres Lara, C. (1994). La constitución económica en el Perú. Lima: Asesorandina SRL. 